\title{
Teratogenicity of Antiepileptic Medications
}

\author{
Benzi M. Kluger, M.D. ${ }^{1}$ and Kimford J. Meador, M.D. ${ }^{1}$ \\ ${ }^{1}$ Department of Neurology, University of Florida, Gainesville, Florida
}

\begin{abstract}
Antiepileptic drugs (AEDs) are frequently used to treat several conditions that are common in women of childbearing age, including epilepsy, headaches, and mood disorders. Moreover, as in the case of epilepsy and severe psychiatric disease, clinicians frequently do not have the option of stopping these medications or switching to another class of drugs. Overall, AEDs have been associated with an increased risk of major congenital malformations, minor anomalies, specific congenital syndromes, and developmental disorders seen in childhood. However, the differential effects of individual AEDs remain uncertain. Data are accumulating which strongly suggest that these risks are highest in patients receiving polypharmacy and valproate. There is also modest evidence to suggest an increased risk for phenobarbital. While other older AEDs appear to carry some teratogenic risk, there is not adequate evidence to further stratify their risk. Clinical and basic science research regarding newer AEDs suggests equivalent, if not safer, profiles compared with older AEDs, but these data are inconclusive. Management of women with epilepsy should include a discussion of these risks, prophylactic treatment with folic acid, and the minimal use of polypharmacy and valproate needed to maintain optimum seizure control.
\end{abstract}

\section{Keywords}

Antiepileptic medications; teratogens; epilepsy; congenital malformations

The first report that antiepileptic drugs (AEDs) may have teratogenic effects dates back over 40 years. ${ }^{1}$ Since that time, considerable evidence has accumulated demonstrating that AED use is associated with an increased risk of congenital malformations ${ }^{2}$ and may have long-term effects on intellectual development during childhood. ${ }^{3}$ The epidemiologic importance of this issue is significant and will continue to grow as these medications become more widely prescribed. In the United States alone, it is estimated that at least 45,000 children were exposed to AEDs in utero. ${ }^{3}$ Unlike many medications, AEDs have the potential to affect fetal development from early in the first trimester through birth. Although the risks of teratogenicity of AEDs are most often discussed in reference to patients with epilepsy, there are currently more women taking AEDs for other indications, such as psychiatric disturbances and headaches.

Several questions should be considered when evaluating the teratogenicity of any medication. ${ }^{4}$ First, are there any genetic or environmental factors that may increase the susceptibility of the fetus? Both maternal epilepsy and seizures have been reported to increase the risk of poor outcomes in children independent of AED use. We will examine this issue as well as research on specific genotypes that may interact with AED teratogenesis during development.

Address for correspondence and reprint requests: Kimford J. Meador, M.D., Melvin Greer Professor of Neurology, Department of Neurology, University of Florida, Box 100236, Gainesville, FL 32610 (Kimford.meador@neurology.ufl.edu).

Epilepsy; Guest Editor, Andres M. Kanner, M.D. 
Second, what are the effects of the drug at different developmental stages? These effects may be categorized as: (1) major congenital malformations (MCMs) that affect the development of major anatomic structures and significantly impair function; (2) minor anomalies that may affect appearance but do not interfere with function; and (3) developmental deficits that impact cognition and/or behavior but are not necessarily associated with visible structural changes. This question is particularly important when it comes to the management of not only pregnant women, but any woman of childbearing age. In answering this question, we will review the effects AEDs have on the developing fetus as well as the potential mechanisms by which these drugs affect fetal development.

Although AEDs may be considered as a class of medications, there is considerable heterogeneity in the molecular structures, specific targets, pharmacological targets, and pharmacodynamic profiles of the individual drugs. ${ }^{5}$ While some AEDs are associated with particular teratogenic syndromes, ${ }^{6,7}$ the majority of abnormalities seen on a population basis are nonspecific. Thus, our third question is whether any particular agents have a greater or lesser risk of teratogenicity. A related question is whether there is a dose-response relationship or threshold of increased risk for a particular AED. Moreover, as patients are frequently on more than one AED, we will examine the literature regarding the risks associated with polypharmacy.

Finally, and perhaps most importantly, is the question of what can be done to prevent or ameliorate the teratogenic risk of AEDs. While the simplest response is to avoid any AED use in women of childbearing age, this is frequently not a reasonable or safe option for many patients with significant epilepsy or psychiatric disease. We will review recommendations and research pertaining to several practical management issues in women on AEDs and pregnancy.

\section{Risks of Not Using Antiepileptic Drugs}

Before examining the teratogenic risks of AEDs, it is important to highlight the benefits to both the mother and fetus. These medications are widely prescribed because they are able to treat many painful and life-threatening conditions effectively. In the case of bipolar mood disorder, pregnancy appears to be a time of particularly high risk for mood episodes and suicide. ${ }^{8}$ While seizure frequency often changes during pregnancy, there is no consistent pattern to this change, with 20 to $33 \%$ of pregnant women experiencing an increase, 10 to $25 \%$ a decrease, and the remainder experiencing no change. ${ }^{9}$ However, the risks of seizures to both the mother and fetus are substantial and should be treated aggressively. Trauma related to seizures and status epilepticus appear to be the leading causes of excess maternal mortality seen in women with epilepsy. ${ }^{10}$ Not uncommonly, women on AEDs will discontinue or reduce the dose of their AED during pregnancy. This places them at increased risk for morbidity due to seizures, but unfortunately does not significantly decrease the risk of MCMs, as much of the risk of AEDs accrues during the first trimester before many women realize they are pregnant.

Although there is no direct evidence of a teratogenic effect of seizures during pregnancy, animal studies have demonstrated hippocampal injury to the fetus, ${ }^{11}$ and clinical studies have shown that even complex partial seizures may induce fetal bradycardia and possibly hypoxia. ${ }^{12}$ While the long-term effects of seizures during pregnancy remain uncertain, one clinical study has reported that neurodevelopmental outcomes and verbal IQ are lower in children of pregnancies affected by five or more generalized tonic-clonic seizures compared with other seizure types or lower frequencies. This effect is significant even when controlling for AED use. ${ }^{13}$

\section{Genetic and Environmental Risk Factors}

Several authors have reported that epilepsy is a risk factor for congenital abnormalities independent of AED use. ${ }^{14}$ This increased risk has been posited to be due to genetic factors 
seen in patients with epilepsy. ${ }^{15}$ While this risk is highest for children of mothers with epilepsy, paternal epilepsy is associated with a smaller, but significant, increased risk of MCMs compared with the general population. ${ }^{16}$ However, a recent meta-analysis of ten studies comparing the pregnancy outcomes of control subjects with treated and untreated women with epilepsy concluded that there is no evidence for an increased risk of malformations associated with epilepsy (odds ratio [OR] 1.92; 95\% confidence interval [CI], 0.92 to 4.00 ). ${ }^{17}$ The OR was significantly elevated in women taking AEDs (OR 3.26; 95\% CI, 2.15 to 4.93). Further analysis of the selected studies suggested that there was a significant publication bias, with smaller studies ( $<100$ subjects) skewed toward positive findings. When these studies were removed, the OR was 0.99 (95\% CI, 0.49 to 2.01). Although untreated women with epilepsy likely differ in many respects from treated women, other studies have shown that women taking AEDs for conditions other than epilepsy have similarly increased rates of malformations. ${ }^{18}$

While epilepsy per se may not confer a significant genetic risk for MCMs, research has shown that pharmacogenetic interactions may increase the risk of malformations in certain women taking AEDs. This was first suggested by studies showing that women taking AEDs who had had prior pregnancies affected by MCMs were more likely to have similar outcomes in future pregnancies compared with the baseline risk of women taking AEDs. ${ }^{19}$ These pharmacogenetic interactions may be due to a reduced ability of the mother to detoxify AED metabolites. ${ }^{20}$

AEDs may also interact with other predisposing genetic factors. A common polymorphism $(677 \mathrm{C} \rightarrow \mathrm{T})$ in the methylene tetrahydrofolate reductase gene (MHTFR) reduces folate metabolism. In the general population, both homozygotes and heterozygotes of this genotype show an increased risk for neural tube defects (NTDs). ${ }^{21}$ In a study of infants born to mothers taking valproic acid (VPA), maternal heterozygotes for this mutation showed an increased risk for NTDs and other MCMs compared with mothers with the normal genotype. ${ }^{22}$ This association was not seen when looking at paternal or fetal genotypes. While it is likely that fetal genotypes are an important factor in teratogenesis, ${ }^{23}$ this has not yet been demonstrated with relation to AEDs.

\section{Effects of AEDs on the Developing Fetus}

Large epidemiological studies have repeatedly demonstrated an increased risk of teratogenesis in mothers taking AEDs. ${ }^{2}$ These studies generally demonstrate an increased risk of MCMs in mothers taking AEDs (4 to 7\%) versus the rate in the general population (2 to $3 \%$ ). ${ }^{9}$ While the most recent recommendations from the American Academy of Neurology ${ }^{24}$ and International League Against Epilepsy ${ }^{25}$ did not distinguish between individual AEDs, there is an accumulating body of evidence to suggest that these risks are significantly greater with VPA, ${ }^{26}$ polypharmacy, ${ }^{27}$ and possibly phenobarbital. ${ }^{28}$

\section{MCMs and the Fetal Antiepileptic Syndrome}

AED exposure prior to 3 weeks' gestation may have adverse effects on the fetus, and this exposure would be expected to result in fetal loss. ${ }^{29}$ In fact, women taking AEDs do have an increased rate of miscarriages and fetal loss. ${ }^{9}$ It is not until the period of organogenesis (weeks 3 to 8) that MCMs occur. ${ }^{29}$ The most common MCMs seen in children exposed to AEDs are similar to MCMs seen in the general population and include cardiac defects, urogenital malformations, craniofacial defects, and skeletal abnormalities. ${ }^{30}$ The only exception to this rule is NTDs, which occur at a higher rate in AED-exposed children, particularly with VPA and carbamazepine. ${ }^{31}$

Several AEDs, including phenytoin, ${ }^{6}$ VPA,${ }^{32}$ carbamazepine, ${ }^{33}$ and phenobarbital, ${ }^{34}$ have been reported to be associated with unique fetal syndromes, broadly referred to as the fetal anticonvulsant syndrome or AED syndrome. ${ }^{7}$ These syndromes are generally similar and include a low or broad nasal bridge, epicanthic folds, hypertelorism, low hairline, and 
hypoplasia of distal phalanges and nails. Given the association of craniofacial and brain development, ${ }^{35}$ it is not surprising that these abnormalities are frequently associated with abnormalities of cognitive development. ${ }^{13}$

\section{Late Neurodevelopmental Effects}

Until recently little was known regarding the long-term outcome of children exposed to AEDs. A cross-sectional retrospective study of 375 children born to mothers with epilepsy made several interesting findings regarding this question. ${ }^{13}$ First, there were no overall group differences between exposed and unexposed children in terms of full scale, verbal, or performance IQ. These scores were in the low normal range, and may have been lower than expected due to selection bias among participants. However, children exposed to VPA had a significant reduction in their verbal IQ and a higher proportion had exceptionally low scores (IQ $<69 ; 22 \%$ in VPA group vs. $8 \%$ with other AEDs). This effect appeared to be related to dose, with a dose threshold of $800 \mathrm{mg}$ per day. Finally, this study has confirmed previous reports of developmental delays associated with craniofacial abnormalities by showing a higher risk of low IQ among children with dysmorphic facies (55\%) compared with normal features (22\%). Similar findings related to verbal IQ have also been reported for phenobarbital. ${ }^{36}$ Another retrospective study of 293 children suggests that in addition to VPA, developmental delays may be associated with polypharmacy, carbamazepine, and phenytoin. ${ }^{37}$ A more recent prospective study found that VPA exposure was associated with worse developmental outcomes at age 2 compared with carbamazepine, lamotrigine, and phenytoin. ${ }^{38}$ Moreover, this effect was related to maternal dose and serum levels. Although anatomic teratogenesis may lead to behavioral issues, isolated behavioral and cognitive teratogenesis likely represents a distinct process beginning in the third trimester and lasting until birth. ${ }^{39}$

\section{Mechanisms of AED Teratogenesis}

Animal studies of AED exposure in utero have provided much insight into the possible teratogenic mechanisms of the various AEDs at different stages of fetal development. As several excellent reviews exist on this topic, ${ }^{7,40,41}$ we will highlight some emerging themes. First, AEDs may exert toxic effects on the developing brain through their regular mechanisms of action. For example, both gamma aminobutyric acid and N-methyl-D-aspartic acid glutamate receptors have been demonstrated to be critical for neuronal migration, and antagonists to these receptors can alter neuronal migration in slice culture and in vivo. ${ }^{40}$ Second, AEDs or their metabolites may directly impact critical regulatory pathways for development. The Wnt signaling pathway allows communication between the cell membrane and nucleus, which is critical to normal fetal development and is highly conserved across species. ${ }^{42}$ VPA has been shown to disrupt this pathway. ${ }^{43}$ Moreover, VPA analogues that do not interact with Wnt do not show teratogenic effects, while other molecules interfering with this pathway produce teratogenic effects similar to VPA. Similarly, several AEDs have been posited to exert their teratogenic effects through inhibiting folate metabolism. ${ }^{44}$ Unfortunately, clinical studies have not demonstrated any alteration in risk to women taking AEDs through folate supplementation, suggesting that low folate levels may only be a marker for the underlying causative mechanism. Finally, there is evidence that a broad range of AEDs may influence brain development by inducing neural apoptosis. Bittigau and colleagues ${ }^{45}$ performed a study in rats examining the effects of therapeutic concentrations of several common AEDs (VPA, phenytoin, clonazepam, phenobarbital, vigabatrin, and diazepam) on brain development. They found that all drugs caused apoptotic neurodegeneration and found evidence to suggest a common mechanism for these AEDs may be through the suppression of an endogenous neuroprotective system, including several neurotrophic factors. As with their antiepileptic modes of action, it is probable that each AED can affect development through multiple mechanisms. 


\section{Risks of MCMs for Specific AEDs}

Valproate-Evidence that VPA may have a greater teratogenic potential than other AEDs was first suggested in the early 1980s by several case series of spina bifida in children exposed to VPA in utero. ${ }^{46}$ In 1997, a large multicenter prospective study of AED exposure reported that VPA appeared to have an increased risk of MCMs versus other AEDs ${ }^{47}$ This study also demonstrated a relationship to VPA dose, with a significantly increased risk occurring for mothers taking more than $1000 \mathrm{mg}$ per day. This finding has been replicated in subsequent publications from several large pregnancy registries, including the North American Pregnancy Registry $^{48}$ (10.7\% vs. $2.9 \%$ other AED monotherapies), the Australian Pregnancy Registry ${ }^{49}$ (17.1\% vs. $2.4 \%$ other AEDs), the Swedish Medical Birth Registry ${ }^{50}$ (9.7\% vs. 4.0\% carbamazepine), the Finnish National Medical Birth Registry ${ }^{51}$ (10.7\% vs. 3.5\% carbamazepine), the United Kingdom Pregnancy Registry 52 (6.2\% vs. $2.2 \%$ carbamazepine), and the International Lamotrigine Pregnancy Registry ${ }^{53}$ (12.5\% polytherapy with valproate vs. $2.7 \%$ polytherapy without valproate). Most recently, the Neurodevelopmental Effects of Antiepileptic Drugs (NEAD) Study Group confirmed both the increased risk of poor fetal outcome (MCM or death) and the dose-dependent effect of VPA in a prospective study (20.3\% with VPA vs. $10.7 \%$ in phenytoin, $8.2 \%$ in carbamazepine, and $1 \%$ in lamotrigine). ${ }^{26}$ Based on their findings and the collective evidence of previous studies, the NEAD study group recommended that VPA not be used as a first-line medication in women in their childbearing years, and that the dose should be limited if used.

Phenobarbital-Phenobarbital is the oldest AED currently in common use. Early studies of its teratogenic effect suggested that it had little teratogenic risk, and less teratogenic risk than other AEDs ${ }^{54}$ However, a more careful examination of this data suggests that the risk of MCMs with phenobarbital was higher than in the general population (11\%) and possibly a doseresponse relationship for doses greater than $60 \mathrm{mg}$ per day. Subsequent studies have demonstrated specific anomalies associated with phenobarbital ${ }^{34}$ as well as evidence of increased risk in large prospective studies. The North American Pregnancy Registry demonstrated a $6.5 \%$ risk among 77 phenobarbital monotherapy exposures compared with a $2.9 \%$ rate among other AEDs and background population rate of $1.6 \% .{ }^{28}$ Given the low cost of phenobarbital, it might be expected that this effect is partially mediated through other known environmental risk factors such as socio-economic status. However, in this study there was no difference in education, maternal IQ, smoking, or alcohol use between mothers taking phenobarbital and other AEDs.

Benzodiazepines-Clinical data suggest that benzodiazepines have, at most, a mild increased risk of MCM. A large meta-analysis of 12 cohort studies, representing over 1000 exposed pregnancies, found no increased risk of MCMs or cleft lip versus controls (OR 0.9; $95 \%$ CI, 0.61 to 1.35 ), including two studies of patients with epilepsy. ${ }^{55}$ However, a metaanalysis of case control studies from the same paper found an increased risk of MCMs (OR $3.01 ; 95 \% \mathrm{CI}, 1.32$ to 6.84 ). Although case-control studies may be more sensitive to rare outcomes, they also suffer from biases (e.g., recall bias). Moreover, several of these casecontrol studies allowed the use of other medications, making the increased risk reported tenuous at best. A more recent study of 52 mothers taking clonazepam found one MCM (3\%) in a patient on monotherapy and none with polytherapy. ${ }^{56}$

Phenytoin-The risks of phenytoin to the developing fetus have been well known and documented for several decades. ${ }^{6}$ This risk has been estimated to be two to three times that of mothers not taking phenytoin as has been confirmed in several recent studies. ${ }^{8,26}$ While several neurodevelopmental studies have suggested an increased risk for phenytoin versus other AEDs, 57 these results are still debatable and may be due to confounds of dosage and maternal IQ. ${ }^{58}$ It is still unknown if phenytoin has a higher risk than newer AEDs because of insufficient 
sample sizes in most newer studies (possibly due to the avoidance of phenytoin in young women for cosmetic reasons).

Carbamazepine and Oxcarbazepine-The risks associated with carbamazepine have generally been similar to phenytoin, with the exception of a higher incidence of NTDs. ${ }^{31}$ Although there are greater numbers of patients taking carbamazepine in recent registries, these data do not consistently demonstrate a differential risk. While there is less clinical experience with oxcarbazepine, a review of reported studies representing over 300 pregnancies exposed to oxcarbazepine found no evidence of an increased risk of MCMs with monotherapy (2.4\%), except when used in polytherapy $(6.6 \%) .59$

Lamotrigine-The latest report from the International Lamotrigine Pregnancy Registry concluded that there is no evidence for an increased risk of MCMs with lamotrigine exposure based on a rate of $2.9 \%$ over 800 exposures. ${ }^{60}$ Similarly, in the most recent NEAD study, lamotrigine compared favorably to other AEDS with a $1 \%$ risk of MCMs and appeared to have no increased risk compared with mothers not taking AEDs. ${ }^{26}$ Although an early analysis of the Lamotrigine Registry suggested a dose-response effect for lamotrigine, ${ }^{53}$ which is highly suggestive of having some teratogenic potential, the more recent logistic analysis of 800 pregnancies was unable to reproduce this result. ${ }^{60}$

Other AEDS-Clinical data regarding other AEDs are quite minimal. The largest study of levetiracetam (117 patients) found no evidence of an increased risk of MCMs. ${ }^{61}$ Only 3 cases of MCM were reported (2.7\%), all of whom were also exposed to other AEDs. To date, only 26 pregnancy outcomes have been reported for zonisamide, with 2 MCMs (7.7\%), both in women on polytherapy. ${ }^{62}$ A study of 51 pregnancies exposed to gabapentin found no increased risk of MCM (2\%) among live births. ${ }^{63}$ With the exception of a handful of case reports, there are few clinical data regarding other AEDs. Animal studies have suggested that gabapentin, topiramate, vigabatrin, and lamotrigine may have teratogenic potential. 4,44,64 However, caution must be applied when interpreting these results, particularly as many of the doses used were supratherapeutic. However, some case reports have demonstrated specific MCMs that appear to support these studies. ${ }^{65}$

Polypharmacy - The vast majority of studies that have compared monotherapy to polypharmacy have found an increased risk of teratogenesis with polypharmacy. ${ }^{27}$ This risk appears to increase with the number of medications, and may also be related to specific combinations of medications. A study of lamotrigine found that the incidence of MCMs associated was significantly higher when it was given with VPA (12.5\%) compared with polypharmacy with other AEDs $(2.7 \%)$, or as monotherapy $(2.9 \%) .{ }^{59}$ The risk of polypharmacy combining only newer AEDs is currently unknown.

\section{Clinical Recommendations for AED Use before and during Pregnancy}

Although the relative risks of MCMs and worse developmental outcomes are increased in women taking AEDs, the absolute risk is low and the majority of women on AEDs will have healthy pregnancies and children. Thus, neither the use of AEDs nor epilepsy should be considered as a contraindication to pregnancy. As approximately half of all pregnancies are unintended, ${ }^{66}$ it is important that clinicians consider issues regarding the effects of medications on pregnancy in all women of childbearing age. This point bears emphasis, as a recent study of physician prescribing patterns shows that less than half of women of childbearing age who receive Class D teratogenic medications receive contraceptive counseling or prescriptions, including for emergency contraception. ${ }^{67}$ 
Given the preponderance of evidence suggesting worse fetal outcomes in women taking VPA, we recommend that other agents be considered first in women of childbearing age. Similar recommendations have been made for patients taking VPA in the setting of bipolar mood disorder. ${ }^{8}$ If other treatments have failed and VPA must be used, we recommend using the lowest dose possible and dividing the dose three times a day or using extended release preparations to avoid high peak levels. Similarly, we would recommend caution in the use of phenobarbital. Although there are insufficient data to clearly recommend one AED over another, we would recommend using the minimal effective dose and avoiding or minimizing polypharmacy when possible.

\section{NTDs and Folic Acid}

There is significant evidence demonstrating the value of folate supplementation in preventing NTD in the general population and in women at high risk due to NTDs in previous pregnancies. ${ }^{68}$ Based on these data, it is recommended that all women of childbearing age take $0.4 \mathrm{mg}$ folate and that high-risk women take $4 \mathrm{mg} .{ }^{69}$ Beyond these general recommendations there is no evidence to show that the risk of NTD can be further reduced by folate supplementation in women taking AEDs. ${ }^{70}$ While low folate levels have been associated with an increased risk of MCMs and NTDs in women on AEDs, ${ }^{70}$ the majority of studies examining folate supplementation have found no decrease in risk, particularly for VPA. ${ }^{71}$ Nevertheless, we recommend $0.4 \mathrm{mg} / \mathrm{day}$ of folate in women of childbearing potential and high-dose folate (1 to $4 \mathrm{mg} /$ day) for women taking VPA or enzyme-inducing AEDs (carbamazepine, phenytoin, and phenobarbital). Appropriate screening for NTDs, including maternal serum $\alpha$-fetoprotein and ultrasonography, is recommended, particularly for women taking VPA and carbamazepine. 72

\section{Recommendations for the Pregnant Patient with Epilepsy}

It is generally not recommended to switch AEDs during pregnancy due to the increased risk of seizures during these transitions. ${ }^{73}$ Similar considerations may apply to AED use for other disorders, such as bipolar mood disorder. ${ }^{74}$ Blood levels should be followed during pregnancy to avoid toxicity, although increased clearance and low levels of AEDs are a more common complication. ${ }^{75}$ Although technically not a teratogenic effect, several AEDs, including phenytoin, carbamazepine, and phenobarbital, can induce a vitamin K deficiency which has been associated with bleeding complications in the fetus and neonate. ${ }^{76}$ Maternal supplementation of 10 to $20 \mathrm{mg}$ vitamin $\mathrm{K}$ per day orally in the last month of pregnancy and $1 \mathrm{mg}$ intramuscularly to the infant at birth have been recommended to prevent bleeding complications. ${ }^{77}$

\section{Areas for Future Research}

While randomized controlled trials cannot be ethically or practically performed to provide answers to the teratogenic potential of AEDs, there are still many avenues to pursue in answering remaining questions. There are currently several large multicenter prospective AED pregnancy registries which have the potential to increase our understanding of individual AEDs, particularly regarding newer agents and developmental outcomes. There is also an effort to carry out longitudinal studies of cognitive development in children exposed to AEDs in utero to better understand the impact of AEDs on cognitive development. Finally, continued animal and in vitro research on teratogenic mechanisms of AEDs is needed to develop safer drugs and better prevention strategies. 


\section{Conclusions}

Our understanding of the clinical risks of AED treatment in pregnancy and the mechanisms underlying AED-induced teratogenesis have advanced significantly over the past decade. It is expected that this research will be reflected in new recommendations for the treatment of women of childbearing age taking AEDs. However, many questions remain unanswered and there is a great need for additional research in this area.

\section{Acknowledgments}

This work was supported by the American Academy of Neurology Foundation Corporate Roundtable Clinical Research Training Fellowship.

\section{References}

1. Mueller-Kueppers M. Embryopathy during pregnancy caused by taking anticonvulsants. Acta Paedopsychiatr 1963;30:401-405. [PubMed: 14093746]

2. Perucca E. Birth defects after prenatal exposure to anti-epileptic drugs. Lancet Neurol 2005;4:781786. [PubMed: 16239185]

3. Motamedi GK, Meador KJ. Antiepileptic drugs and neurodevelopment. Curr Neurol Neurosci Rep 2006;6:341-346. [PubMed: 16822356]

4. Palmieri C, Canger R. Teratogenic potential of the newer antiepileptic drugs: what is known and how should this influence prescribing? CNS Drugs 2002;16:755-764. [PubMed: 12383031]

5. Rogawski MA, Loscher W. The neurobiology of antiepileptic drugs. Nat Rev Neurosci 2004;5:553564. [PubMed: 15208697]

6. Hanson JW, Smith DW. The fetal hydantoin syndrome. J Pediatr 1975;87:285-290. [PubMed: 50428]

7. Ornoy A. Neuroteratogens in man: an overview with special emphasis on the teratogenicity of antiepileptic drugs in pregnancy. Reprod Toxicol 2006;22:214-226. [PubMed: 16621443]

8. Freeman MP, Gelenberg AJ. Bipolar disorder in women: reproductive events and treatment considerations. Acta Psychiatr Scand 2005;112:88-96. [PubMed: 15992389]

9. Pennell PB. Pregnancy in women who have epilepsy. Neurol Clin 2004;22:799-820. [PubMed: 15474768]

10. Barrett C, Richens A. Epilepsy and pregnancy: report of an Epilepsy Research Foundation Workshop. Epilepsy Res 2003;52:147-187. [PubMed: 12536051]

11. Hallak M, Kupsky WJ, Hotra JW, et al. Fetal rat brain damage caused by maternal seizure activity: prevention by magnesium sulfate. Am J Obstet Gynecol 1999;181:828-834. [PubMed: 10521737]

12. Nei M, Daly S, Liporace J. A maternal complex partial seizure in labor can affect fetal heart rate. Neurology 1998;51:904-906. [PubMed: 9748057]

13. Adab N, Kini U, Vinten J, et al. The longer term outcome of children born to mothers with epilepsy. J Neurol Neurosurg Psychiatry 2004;75:1575-1583. [PubMed: 15491979]

14. Partington MD, McLone DG. Hereditary factors in the etiology of neural tube defects: results of a survey. Pediatr Neurosurg 1995;23:311-316. [PubMed: 8744000]

15. Duncan S, Mercho S, Lopes-Cendes I, et al. Repeated neural tube defects and valproate monotherapy suggest a pharmacogenetic abnormality. Epilepsia 2001;42:750-753. [PubMed: 11422330]

16. Kallen, B. Epidemiology of Human Reproduction. Boca Raton: CRC Press; 1988. p. 133-137.

17. Fried S, Kozer E, Nulman I, et al. Malformation rates in children of women with untreated epilepsy: a meta-analysis. Drug Saf 2004;27:197-202. [PubMed: 14756581]

18. Holmes LB, Harvey EA, Coull BA, et al. The teratogenicity of anticonvulsant drugs. N Engl J Med 2001;344:1132-1138. [PubMed: 11297704]

19. Lindhout D, Omtzigt JG. Pregnancy and the risk of teratogenicity. Epilepsia 1992;33(suppl 4):S41S48. [PubMed: 1425493]

20. Strickler SM, Dansky LV, Miller MA, et al. Genetic predisposition to phenytoin-induced birth defects. Lancet 1985;2:746-749. [PubMed: 2864485] 
21. Van der Put NM, Eskes TK, Blom HJ. Is the common 677C $\rightarrow$ T mutation in the methylenetetrahydrofolate reductase gene a risk factor for neural tube defects? A meta-analysis. QJM 1997;90:111-115. [PubMed: 9068801]

22. Dean JC, Moore SJ, Osborne A, et al. Fetal anticonvulsant syndrome and mutation in the maternal MTHFR gene. Clin Genet 1999;56:216-220. [PubMed: 10563481]

23. Finnell RH, Waes JG, Eudy JD, et al. Molecular basis of environmentally induced birth defects. Annu Rev Pharmacol Toxicol 2002;42:181-208. [PubMed: 11807170]

24. Practice parameter: Management issues for women with epilepsy (summary statement). Report of the Quality Standards Subcommittee of the American Academy of Neurology. Neurology 1998;51:944-948. [PubMed: 9781510]

25. Guidelines for the care of women of childbearing age with epilepsy. Commission on Genetics, Pregnancy, and the Child, International League Against Epilepsy. Epilepsia 1993;34:588-589. [PubMed: 8330564]

26. Meador KJ, Baker GA, Finnell RH, et al. In utero antiepileptic drug exposure: fetal death and malformations. Neurology 2006;67:407-412. [PubMed: 16894099]

27. Pennell PB. The importance of monotherapy in pregnancy. Neurology 2003;60(suppl 4):S31-S38. [PubMed: 12796519]

28. Holmes LB, Wyszynski DF, Lieberman E. The AED (antiepileptic drug) pregnancy registry: a 6-year experience. Arch Neurol 2004;61:673-678. [PubMed: 15148143]

29. Polifka JE, Friedman JM. Medical genetics: 1. Clinical teratology in the age of genomics. CMAJ 2002;167:265-273. [PubMed: 12186175]

30. Finnell, RH.; Nau, H.; Yerby, MS. General principles: teratogenicity of antiepileptic drugs. In: Levy, RH.; Matson, BS., editors. Antiepileptic Drugs. Vol. 4th. New York, NY: Raven Press; 1995. p. 209-230.

31. Lindhout D, Omtzigt JG. Teratogenic effects of antiepileptic drugs: implications for the management of epilepsy in women of childbearing age. Epilepsia 1994;35(suppl 4):S19-S28. [PubMed: 8174516]

32. Ardinger HH, Atkin JF, Blackston RD, et al. Verification of the fetal valproate syndrome phenotype. Am J Med Genet 1988;29:171-185. [PubMed: 3125743]

33. Jones KL, Lacro RV, Johnson KA, et al. Pattern of malformations in the children of women treated with carbamazepine during pregnancy. N Engl J Med 1989;320:1661-1666. [PubMed: 2725616]

34. Jones KL, Johnson KA, Chambers CC. Pregnancy outcome in women treated with phenobarbital monotherapy. Teratology 1992;45:453-454.

35. Wilkie AO, Morris-Kay GM. Genetics of craniofacial development and malformation. Nat Rev Genet 2001;2:458-468. [PubMed: 11389462]

36. Reinisch JM, Sanders SA, Mortensen EL, et al. In utero exposure to phenobarbital and intelligence deficits in adult men. JAMA 1995;274:1518-1525. [PubMed: 7474220]

37. Dean JC, Hailey H, Moore SJ, et al. Long-term health and neurodevelopment in children exposed to antiepileptic drugs before birth. J Med Genet 2002;39:251-259. [PubMed: 11950853]

38. Meador KJ, Browning N, Cohen MJ, et al. Cognitive outcomes at 2 years old in children of women with epilepsy differ as function of in utero antiepileptic drug. Neurology 2007;68(suppl 1):A337.

39. Schaefer GB, Sheth RD, Bodensteiner JB. Cerebral dysgenesis: an overview. Neurol Clin 1994;12:773-788. [PubMed: 7845342]

40. Marsh ED, Brooks-Kayal AR, Porter BE. Seizures and antiepileptic drugs: does exposure alter normal brain development? Epilepsia 2006;47:1999-2010. [PubMed: 17201696]

41. Kaindl AM, Asimiadou S, Manthey D, et al. Antiepileptic drugs and the developing brain. Cell Mol Life Sci 2006;63:399-413. [PubMed: 16389461]

42. Cadigan KM, Nusse R. WNT signaling: a common theme in animal development. Genes Dev 1997;11:3286-3305. [PubMed: 9407023]

43. Wiltse J. Mode of action: inhibition of histone deacetylase, altering WNT-dependent gene expression, and regulation of beta-catenin-developmental effects of valproic acid. Crit Rev Toxicol 2005;35(89):727-738. [PubMed: 16417040]

44. Dansky LV, Rosenblatt DS, Andermann E. Mechanisms of teratogenesis: folic acid and antiepileptic therapy. Neurology 1992;42(suppl 5):S32-S42. 
45. Bittigau P, Sifringer M, Genz K, et al. Antiepileptic drugs and apoptotic neurodegeneration in the developing brain. Proc Natl Acad Sci U S A 2002;99:15089-15094. [PubMed: 12417760]

46. Bjerkedal T, Czeizel A, Goujard J, et al. Valproic acid and spina bifida. Lancet 1982;2:1096. [PubMed: 6127554]

47. Samren EB, van Duijn CM, Koch S, et al. Maternal use of antiepileptic drugs and the risk of major congenital malformations: a joint European prospective study of human teratogenesis associated with maternal epilepsy. Epilepsia 1997;38:981-990. [PubMed: 9579936]

48. Wyszynski DF, Nambisan M, Surve T, et al. Antiepileptic Drug Pregnancy Registry. Increased rate of major malformations in offspring exposed to valproate during pregnancy. Neurology 2005;64:961-965. [PubMed: 15781808]

49. Vajda FJ, Eadie MJ. Maternal valproate dosage and foetal malformations. Acta Neurol Scand 2005;112:137-143. [PubMed: 16097954]

50. Wide K, Winbladh B, Kallen B. Major malformations in infants exposed to antiepileptic drugs in utero, with emphasis on carbamazepine and valproic acid: a nation-wide population-based register study. Acta Paediatr 2004;93:174-176. [PubMed: 15046269]

51. Artama M, Auvinen A, Raudaskoski T, et al. Antiepileptic drug use of women with epilepsy and congenital malformations in offspring. Neurology 2005;64:1874-1878. [PubMed: 15955936]

52. Morrow J, Russell A, Guthrie E, et al. Malformation risks of anti-epileptic drugs in pregnancy: a prospective study from the UK Epilepsy and Pregnancy Register. J Neurol Neurosurg Psychiatry 2006;77:193-198. [PubMed: 16157661]

53. Cunnington M, Tennis PInternational Lamotrigine Pregnancy Registry Scientific Advisory Committee. Lamotrigine and the risk of malformations in pregnancy. Neurology 2005;64:955-960. [PubMed: 15781807]

54. Fedrick J. Epilepsy and pregnancy: a report from the Oxford Record Linkage Study. BMJ 1973;2:442448. [PubMed: 4712481]

55. Dolovich LR, Addis A, Vaillancourt JM, et al. Benzodiazepine use in pregnancy and major malformations or oral cleft: meta-analysis of cohort and case-control studies. BMJ 1998;317:839843. [PubMed: 9748174]

56. Lin AE, Peller AJ, Westgate MN, et al. Clonazepam use in pregnancy and the risk of malformations. Birth Defects Res A Clin Mol Teratol 2004;70:534-536. [PubMed: 15329832]

57. Scolnik D, Nulman I, Rovet J, et al. Neurodevelopment of children exposed in utero to phenytoin and carbamazepine monotherapy. JAMA 1994;271:767-770. [PubMed: 7509419]

58. Loring DW, Meador KJ, Thompson WO. Neurodevelopment after in utero exposure to phenytoin and carbamazepine. JAMA 1994;272:850-851. [PubMed: 7521402]

59. Montouris G. Safety of the newer antiepileptic drug oxcarbazepine during pregnancy. Curr Med Res Opin 2005;21:693-701. [PubMed: 15969868]

60. Cunnington M, Ferber S, Quartey GInternational Lamotrigine Pregnancy Registry Scientific Advisory Committee. Effect of dose on the frequency of major birth defects following fetal exposure to lamotrigine monotherapy in an international observational study. Epilepsia 2007;48:1207-1210. [PubMed: 17381445]

61. Hunt S, Craig J, Russell A, et al. Levetiracetam in pregnancy: preliminary experience from the UK Epilepsy and Pregnancy Register. Neurology 2006;67:1876-1879. [PubMed: 17130430]

62. Ohtahara S, Yamatogi Y. Erratum to "Safety of zonisamide therapy: prospective follow-up survey". Seizure 2007;16:87-93. [PubMed: 17269155]

63. Montouris G. Gabapentin exposure in human pregnancy: results from the Gabapentin Pregnancy Registry. Epilepsy Behav 2003;4:310-317. [PubMed: 12791334]

64. Marchi NS, Azoubel R, Tognola WA. Teratogenic effects of lamotrigine on rat fetal brain: a morphometric study. Arq Neuropsiquiatr 2001;59:362-364. [PubMed: 11460180]

65. Vila Cerén C, Demestre Guasch X, Raspall Torrent F, et al. Topiramate and pregnancy: neonate with bone anomalies. An Pediatr (Barc) 2005;63:363-365. [PubMed: 16219257]

66. Finer LB, Henshaw SK. Disparities in rates of unintended pregnancy in the United States, 1994 and 2001. Perspect Sex Reprod Health 2006;38:90-96. [PubMed: 16772190] 
67. Schwarz EB, Postlethwaite DA, Yun-yi H, et al. Documentation of contraception and pregnancy when prescribing potentially teratogenic medications for reproductive-age women. Ann Intern Med 2007;147:370-376. [PubMed: 17876020]

68. Pitkin RM. Folate and neural tube defects. Am J Clin Nutr 2007;85:285S-288S. [PubMed: 17209211]

69. Centers for Disease Control. Recommendations for the use of folic acid to reduce the number of cases of spina bifida and other neural tube defects. MMWR Recomm Rep 1992;41:1-7.

70. Yerby MS. Management issues for women with epilepsy: neural tube defects and folic acid supplementation. Neurology 2003;61(suppl 2):S23-S26. [PubMed: 14504306]

71. Kaaja E, Kaaja R, Hiilesmaa V. Major malformations in offspring of women with epilepsy. Neurology 2003;60:575-579. [PubMed: 12601095]

72. Vajda FJ, Eadie MJ. Maternal valproate dosage and foetal malformations. Acta Neurol Scand 2005;112:137-143. [PubMed: 16097954]

73. Pennell PB. Pregnancy in the woman with epilepsy: maternal and fetal outcomes. Semin Neurol 2002;22:299-308. [PubMed: 12528055]

74. Eberhard-Gran M, Eskild A, Opjordsmoen S. Treating mood disorders during pregnancy: safety considerations. Drug Saf 2005;28:695-706. [PubMed: 16048355]

75. Pennell PB. Antiepileptic drug pharmacokinetics during pregnancy and lactation. Neurology 2003;61 (suppl 2):S35-S42. [PubMed: 14504308]

76. Moslet U, Hansen ES. A review of vitamin K, epilepsy and pregnancy. Acta Neurol Scand 1992;85:39-43. [PubMed: 1546532]

77. Autret-Leca E, Jonville-Béra AP. Vitamin K in neonates: how to administer, when and to whom. Paediatr Drugs 2001;3:1-8. [PubMed: 11220402] 